\title{
Effects of Estrogen Agonists on Amphetamine-Stimulated Striatal Dopamine Release
}

\author{
LI XIAO, ${ }^{1,2}$ AND J ILL B. BECKER $\mathbf{R}^{1,2,3 *}$ \\ ${ }^{1}$ Department of Psychology, TheUniversity of Michigan, Ann Arbor, Michigan 48109-1109 \\ ${ }^{2}$ Reproductive Sciences Program, TheU niversity of Michigan, Ann Arbor, Michigan 48109-1109 \\ ${ }^{3}$ Neuroscience Program, TheUniversity of Michigan, Ann Arbor, Michigan 48109-1109
}

\begin{abstract}
KEY WORDS estrogen agonists; striatum; hormone replacement therapy; dopamine
ABSTRACT Based upon the observation that estrogen acts in the striatum to rapidly modulate dopamine (DA) neural transmission and DA-mediated behaviors, it has been postulated that these effects of estrogen are mediated by a specific, membrane-bound receptor mechanism. To further characterize the pharmacol ogical specificity of the estrogen binding site, the present experiments examine effects of various estrogen agonists on amphetamine (AMPH)-induced DA rel ease from striatal tissue of ovariectomized female rats, using a superfusion method. Catechol estrogens 4-, and 2-hydroxyestradiol, but not 2-methoxyestradiol, significantly enhance AM PH-induced striatal DA release. Estrogen metabolites, estrone and estriol, and the non-steroidal estrogen analog, diethylstilbestrol, are without effects. Estradiol conjugated to bovine serum al bumin (BSA) mimics the effect of estradiol to enhance stimulated striatal DA release. These results indicate that the steroidal configuration and hydroxylation on the A-ring of estrogenic compounds may be important determinants of ligand binding to the putative estrogen binding site in the striatum. Furthermore, the effectiveness of the estradiol conjugated to BSA reinforces the idea of an external membrane-bound receptor binding site in the striatum. Synapse 29:379-391, 1998. @ 1998 Wiley-Liss, Inc.
\end{abstract}

\section{INTRODUCTION}

Accumulating evidence has demonstrated that estrogen can affect the neurochemical and behavioral indices of dopaminergic activity in the striatum. For example, estrogen treatments in ovariectomized (OVX) rats rapidly increase dopamine (DA) turnover (Di Paolo et al., 1985), as well as striatal DA release in vivo and associated behavior (Becker, 1990a; Castner et al., 1993). Direct application of estrogen to the striatum improves performance of OVX rats on a task that requires sensorimotor coordination (Becker et al., 1987). In vitro, estrogen at a physiologically relevant dose stereospecifically potentiates $\mathrm{K}^{+}$- and amphetamine (AMPH)-evoked DA release from striatal tissue of OVX rats (Becker, 1990b). Most of these effects occur with a more rapid onset and shorter duration than would be expected if mediated by the classical estrogen receptor.

The mechanism by which estrogen exerts these seemingly nongenomic effects is not fully understood as cells in the striatum do not concentrate estrogen intracellularly (Pfaff and Keiner, 1973; Simerly et al., 1990; Stumpf and Sar, 1976). However, in addition to inducing gene expression via the intracellular receptor, estro- gen can produce specific effects through various mechanisms, including specific binding to cell membranes (Heritage et al., 1980; Liu and Patino, 1993; McE wen, 1979, 1994; Nabekura et al., 1986; Tischkau and Ramirez, 1993; Towle and Sze, 1983; Wong and Moss, 1991). More recently, a study employing whole-cell clamp recording has shown that $17 \beta$-estradiol $\left(17 \beta-\mathrm{E}_{2}\right)$ at a very low dose (1-100 pM) inhibits L-type calcium current in acutely dissociated striatal neurons. The reduction of calcium current occurs within 100 milliseconds, and the $17 \alpha$ isomer is not as effective as $17 \beta-\mathrm{E}_{2}$ (Mermelstein et al., 1996). These data indicate that estrogen acts directly in the striatum via a novel estrogen receptor-mediated mechanism to enhance striatal DA functions (Mermelstein et al., 1996). Furthermore, $17 \beta-\mathrm{E}_{2}$ conjugated to bovine serum albumin, which renders $17 \beta-E_{2}$ membrane impermeable (Black-

Contract grant sponsor: NSF ; Contract grant number: BNS9021900; Contract grant number: NICHD5T32-HD07048.

*Correspondence to: J ill B. Becker, Psychology Department, Biopsychology Area, 525 East University, Ann Arbor, MI 48109-1109.

E-mail: jbbecker@umich.edu

Received 11 September 1997; Accepted in revised form 30 J anuary 1998 
more et al., 1991; Ke and Ramirez, 1990; Zheng et al., 1996), mimics the effect of $17 \beta-E_{2}$ on the reduction of calcium current (Mermelstein et al., 1996). Furthermore, this effect is prolonged when GTP- $\gamma$-S is present intracellularly to inhibit inactivation of the G-protein complex (Mermelstein et al., 1996). These observations suggest that the putative estrogen binding site may be located on the extracellular surface of the cell membrane and act via a G-protein-coupled mechanism (Mermelstein et al., 1996).

The present experiments were designed to characterize the pharmacological specificity of the putative estrogen binding site in the striatum. To do so, several agents known to be estrogen agonists and antagonists at the classical estrogen receptor were examined for their effectiveness on AMPH-stimulated DA rel ease in vitro. These compounds are of interest because they are the biological metabolites of estradiol, with specific modification in their chemical structures. For this reason, they have been used as valuable tools to decipher the mechanisms of estrogen actions at molecular, physi ol ogical, and behavioral levels (Martucci and Fishman, 1976,1979; Merriam et al., 1980; Naish and Ball, 1981; Paul and Skolnick, 1977). From a pharmacological point of view, information pertaining to configurations of the hormone structure that are important for the recognition of the hormone by the receptor will help develop more specific pharmacological agents to facilitate isolation of the receptor.

\section{MATERIALS AND METHODS Animals}

Adult female Spraque-Dawley rats weighing 180$200 \mathrm{~g}$ upon arrival were purchased from Harland Spraque Dawl ey Inc. (I ndianapolis, I N), or raised at the University of Michigan (Reproductive Sciences Program, Ann Arbor, MI). They were housed 2-3 per cage with food and water availableall the time. Lighting was maintained on a 14 hour light:10 hour dark schedule (lights on at 0600 hour). All the animals were bilaterally ovariectomized under methoxyflurane anesthesia 2-3 weeks prior to superfusion experiments. Vaginal lavage data were collected daily for at least 10 consecutive days starting 5-7 days after ovariectomy. Only animals that did not have cornified epithelial cells in the vaginal smears during this time were included in the experiments.

\section{Superfusion Procedure}

Superfusion experiments were performed using an automated superfusi on system (Brandel Inc., Gaithersburg, MD). A Ringer's solution ( $145.0 \mathrm{mM} \mathrm{NaCl}, 2.7 \mathrm{mM}$ $\mathrm{KCl}_{2}, 1.2 \mathrm{mM} \mathrm{CaCl} 2,1.0 \mathrm{MgCl}_{2}, 10.0 \mathrm{mM}$ glucose, 0.25 $\mathrm{mM}$ ascorbic acid) was oxygenated by bubbling with $95 \% \mathrm{O}_{2} / 5 \% \mathrm{CO}_{2}$ for 30 minutes, and the $\mathrm{pH}$ was adjusted to 7.4 .
On the day of the superfusion experiment, animals were decapitated, and the brain was quickly removed and placed in ice-cold Ringer's solution. The striatum was dissected and a coronal slice of $3 \mathrm{~mm}$ thickness was cut on an ice-cold rat brain slicer (Becker, 1990b). Striatal tissue obtained from 9-10 animals was pooled, cut into approximately $1 \mathrm{~mm}^{3}$ fragments, and placed into superfusion chambers containing Ringer's solution. Effluent samples were collected throughout the treatment at 5-minute intervals in glass collection vials. Following a 60-minute stabilization period with Ringer's, three baseline samples were collected. This was followed by a period of 35-minute incubation with solutions containing the tested compounds (see below for details). Control chambers were run in parallel. A 2.5-min infusion of $10 \mu \mathrm{M}$ d-amphetamine (AMPH) was then delivered to all the chambers at the end of incubation period. Additional 5-minute samples were collected for 25 minutes following AMPH stimulation. All media were continually infused into the chambers at a flow rate of $100 \mu \mathrm{l} / \mathrm{minute}$, and warmed to $37^{\circ} \mathrm{C}$ in a water bath prior to reaching the chambers. Each collection vial contained $25 \mu \mathrm{l}$ of $0.05 \mathrm{~N} \mathrm{HClO}_{4}$ with dihydroxybenzylamine (DHBA; final concentration $2 \mathrm{ng} / \mathrm{ml}$ ) as an internal standard to control for any variation in volume and loss of DA due to oxidation. Striatal tissue in each chamber was removed and weighed immediately following the superfusion.

$17 \beta-E_{2}$ has been previously shown to potentiate $\mathrm{K}^{+}$-induced striatal DA rel ease most effectively at 100 $\mathrm{pg} / \mathrm{ml}$ (370 pM) using this superfusion system (Becker, 1990b). Therefore, certain estrogen metabolites and analogs were tested at concentrations equimolar to the effective dose of $17 \beta-E_{2}$. Higher or lower doses were also used when the equimolar dose did not show a significant effect. These compounds are depicted in Figure 1. The doses tested are the following: catechol estrogens 4-hydroxyestradiol $\left(4-\mathrm{OHE}_{2} ; 185 \mathrm{pM} ; 740\right.$ $\mathrm{pM}), 2$-hydroxyestradiol $\left(2-\mathrm{OHE}_{2} ; 185 \mathrm{pM} ; 740 \mathrm{pM}\right)$, and 2-methoxyestradiol (2-MeE $2 ; 210 \mathrm{pM} ; 2,100 \mathrm{pM})$; estrogen metabolites estrone (210 pM; 2,100 pM) and estriol (370 pM; 3,700 pM); the non-steroidal estrogen anal og diethyl stil bestrol (DES; 370 pM ; 1850 pM ; 3,700 $\mathrm{pM})$; and $17 \beta-\mathrm{E}_{2}$ covalently conjugated to bovine serum albumin (E-BSA). Compounds (except E-BSA) were dissolved in absolute ethanol as concentrated stocks $(3.7 \mathrm{mM})$ on the day of superfusion immediately prior to striatal tissue preparation and then serially diluted to their final concentrations. Final solutions of these compounds all contained $0.001 \%$ ethanol, and this concentration of ethanol has been found to have no effects on basal or AMPH-induced striatal DA release. For E-BSA, Ringer's was used as vehicle and BSA as the control solution. The concentration of E-BSA (510 $\mathrm{pM}$ ) was calculated in a way so that the final solution contained $100 \mathrm{pg} / \mathrm{ml} 17 \beta-\mathrm{E}_{2}$. 


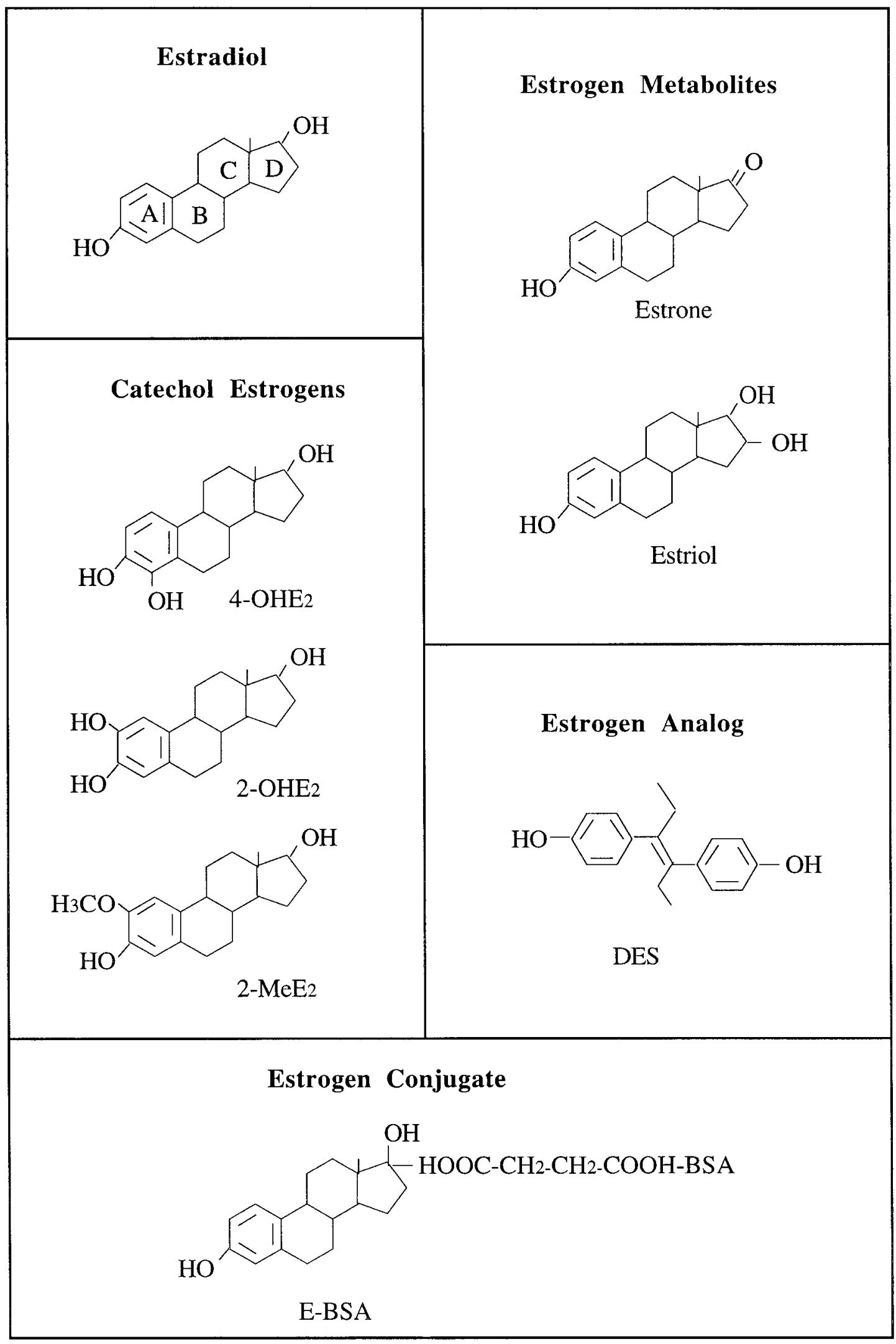

Fig. 1. Chemical structures of the tested compounds and $17 \beta$-estradiol. 

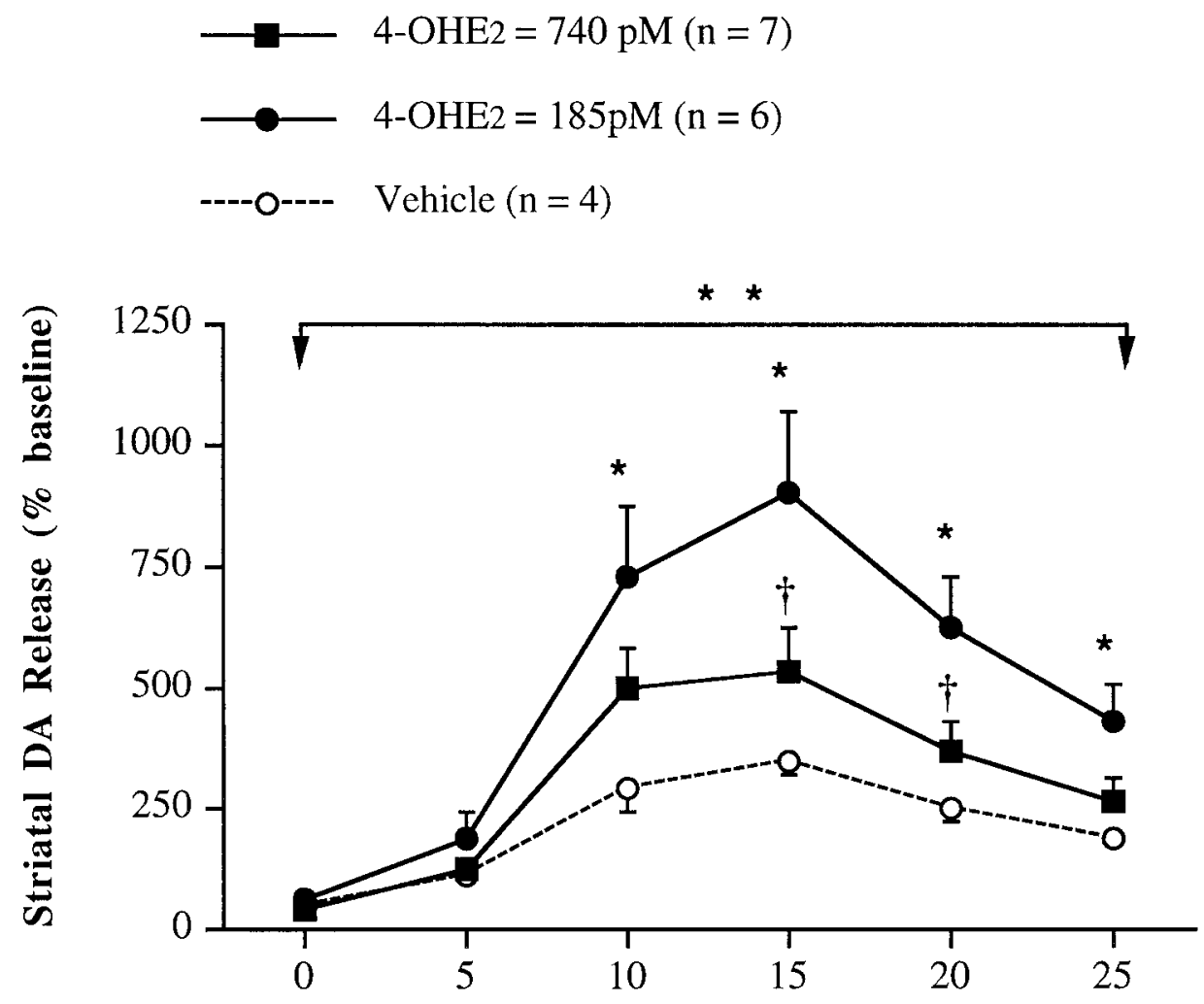

Time Post-AMPH (minutes)

Fig. 2. Time course of $A M P H$-induced DA release in vitro from superfused striatal tissue fragments obtained from OVX rats. Following a 60-minute equilibrium period, effluent samples were collected at 5-minute intervals. Values represent means + SEM (vertical bars) of percentage of baseline, which was determined as the average of effluent DA concentrations $(\mathrm{pg} / \mathrm{mg} / \mathrm{min})$ in the first 3 samples. The

\section{DAAssay and Data Analysis}

DA concentrations in the effluent samples were analyzed using a high performance liquid chromatography system with electrochemical detection (HPLC-EC; ESA, Chelmsford, MA). Baseline DA release was defined as the mean DA rel ease rate $(\mathrm{pg} / \mathrm{mg} / \mathrm{min})$ of the first three effluent samples. The mean DA release rate during intervals following baseline, but prior to AMPH stimulation (Pre-AMPH), was also determined. AMPHstimulated DA rel ease (Post-AMPH) was expressed as a percentage of the initial baseline. For each individual experiment, a two-way analysis of variation (ANOVA) with repeated measures (Time $x$ Treatment) was performed to compareAMPH-stimulated DA release among treatment groups. A one-way ANOVA was used to determine whether there were group differences in DA release rate during baseline, as well as during intervals prior toAMPH stimulation. Post-hoc comparisons (Fisher's PLSD) and Student's t-tests were performed to determine differences between specific treatment groups if the ANOVA indicated a significant overall effect $(P<$ interval when an infusion of d-AMPH $(10 \mu \mathrm{M})$ for 2.5 minutes was given was designated as time $0 . * *$ Significant main effect of treatment $(P<.05)$ and effect of Treatment $x$ Time interaction $(P<.0005)$. $*$ Significantly different from Vehicle group $(P<.03)$. †Significantly different from $185 \mathrm{pM}$ group $(\mathrm{P}<.05)$.

0.05). All statistical analyses were performed on a Macintosh computer using StatView 4.5.

\section{Chemicals}

The following compounds were obtained from Sigma Chemicals (St. Louis, MO) or Steraloids Inc. (Wilton, $\mathrm{NH}$ ): $17 \beta-\mathrm{E}_{2}$, estrone, estriol, 2-hydroxyestradiol, 4-hydroxyestradiol, 2-methoxyestradiol, diethylstilbestrol (DES), 17 $\beta-E_{2}$ 17-hemisuccinate:BSA (E-BSA), and d-amphetamine. Methoxyflurance was purchased from Pitman-Moore (Mundelein, IL).

\section{RESULTS Catechol Estrogens}

Both of the catechol estrogens $4-\mathrm{OHE}_{2}$ and $2-\mathrm{OHE}_{2}$, but not the methylated ether $2-\mathrm{MeE}_{2}$, significantly enhanced the AMPH-stimulated striatal DA release, although with different potencies. The time course of DA release from tissue treated with $740 \mathrm{pM}$ and $185 \mathrm{pM}$ $4-\mathrm{OHE}_{2}$ or vehicle is presented in Figure 2. Treatment 


$$
\begin{array}{ll}
\longrightarrow & 2-\mathrm{OHE} 2=740 \mathrm{pM}(\mathrm{n}=7) \\
\longrightarrow & 2-\mathrm{OHE} 2=185 \mathrm{pM}(\mathrm{n}=6) \\
-\cdots--- & \text { Vehicle }(\mathrm{n}=5)
\end{array}
$$

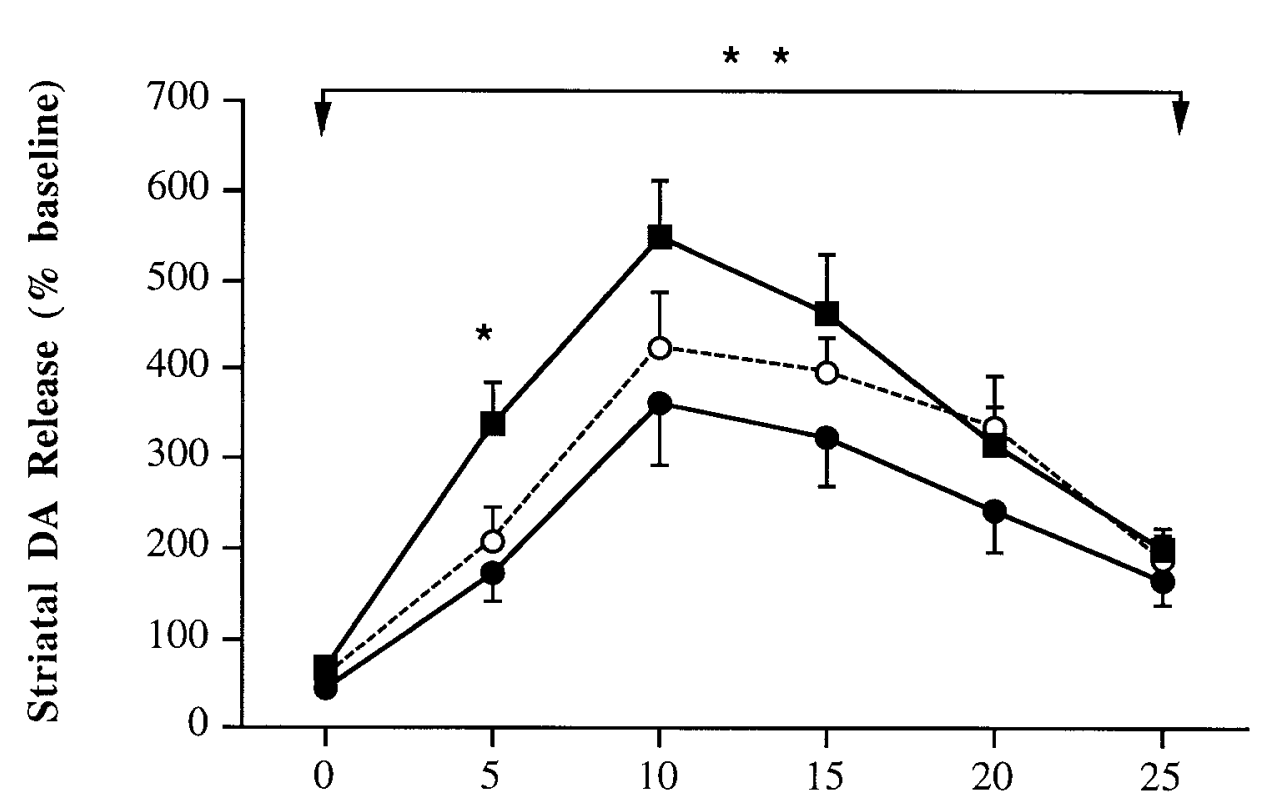

\section{Time Post-AMPH (minutes)}

Fig. 3. Time course of $A M P H$-induced DA rel ease from striatal tissue treated with $2-\mathrm{OHE}_{2}$ at $185 \mathrm{pM}$, $740 \mathrm{pM}$, or vehicle. Treatment procedure was the same as described in Figure 2 . **Significant effect of Time x Treatment interaction on AMPH-induced DA release among the groups $(P<.05)$, which indicated a significantly higher DA release by the higher dose of $2-\mathrm{OHE}_{2}$ than both the lower dose and Vehicle groups at 5 minutes following.

with this compound resulted in a significant overall effect of treatment $\left(\mathrm{F}_{2,14}=3.97, \mathrm{P}<0.05\right)$, and a significant Treatment $\times$ Time interaction $\left(F_{8,56}=4.31\right.$, $\mathrm{P}<0.0005)$. Post-hoc comparisons indicated greater DA rel ease in the group that received $185 \mathrm{pM}(P<0.02)$ than in the control group $(P<0.02)$ or in the group that received $740 \mathrm{pM}(P=0.06)$. Further examination of each Post-AMPH interval found that DA release from striatal tissue treated with $185 \mathrm{pM} 4-\mathrm{OHE}_{2}$ was significantly greater than that from vehicle-treated tissue at 10 minutes after $\mathrm{AMPH}$ stimulation and thereafter $(P<0.03)$. It was also greater than that of the $740 \mathrm{pM}$ $4-\mathrm{OHE}_{2}$ group at 15 and 20 minutes $(P<0.05)$ fol lowing $\mathrm{AMPH}$.

2-OHE 2 was less potent than 4-OHE 2 in its effects on AMPH-stimulated DA rel ease from striatal tissue ( $F$ ig. 3). Treatments with this compound did not result in a significant main effect $\left(F_{2,15}=2.05, P>0.09\right)$. However, there was a significant Treatment $x$ Time interaction $\left(F_{8,60}=2.11, P<0.05\right)$. This difference was observed only at the first 5 minutes post-AMPH interval where $\mathrm{AMPH}$-induced DA release was greater after
$740 \mathrm{pM} 2-\mathrm{OHE}_{2}$ than after treatment with $185 \mathrm{pM}$ $2-\mathrm{OHE}_{2}(\mathrm{P}<0.02)$ or vehicle $(\mathrm{P}<0.05)$.

Figure 4 depicts the effect of $2-\mathrm{MeE}_{2}$ on the striatal DA release. Unlike the hydroxylated estradiol compounds, this methylated catechol estrogen at concentrations of 210 and 2,100 pM did not have any effect on DA release elicited by AMPH $\left(F_{2,15}=.37, \mathrm{P}>0.69\right)$. In addition, in each of these experiments testing the catechol estrogen compounds, there was no difference in baseline or PreAMPH DA release among the treatment groups (Table 1 ).

\section{Estrogen Metabolites and a Non-Steroidal Estrogen Analog}

Neither of the estrogen metabolites, estrone or estriol, nor the non-steroidal estrogen analog DES showed any significant estrogenic effect on AMPH-stimulated DA rel ease. As shown in Figure 5, DA release el icited by AMPH from striatal tissue treated with $210 \mathrm{pM}$ (Fig. $5 \mathrm{~A}$ ) or 2,100 pM (Fig. 5B) estrone did not differ from that of the controls $\left(F_{1,6}=.10, P>0.70 ; F_{1,9}=.46, P>\right.$ 


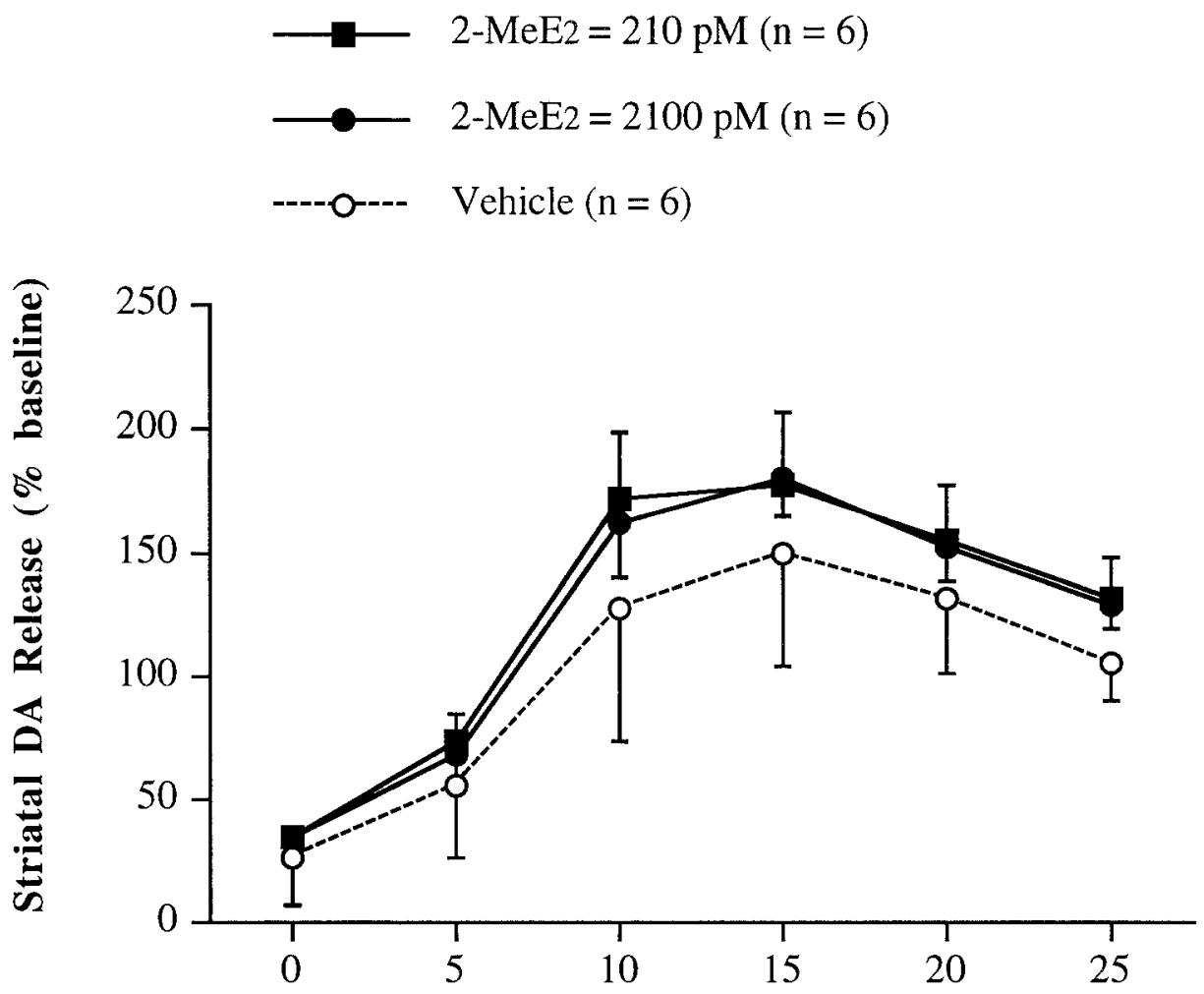

Time Post-AMPH (minutes)

Fig. 4. Time course of $A M P H$-induced striatal DA release showing the effect of 2-MeE 2 . Treatment procedure was the same as described in Figure 2, but with $210 \mathrm{pM}$ and $2.1 \mathrm{nM}$ of 2-MeE 2 . There was no significant difference observed.

0.50 , respectively). Similarly, estriol at 370 or 3,700 pM did not significantly affect the striatal $\mathrm{DA}$ release induced by AMPH $\left(\mathrm{F}_{2,6}=1.20, \mathrm{P}>0.30 ; \mathrm{Fig} .6\right)$.

The results for the effect of DES on striatal DA release are shown in Figure 7. At a concentration equimolar to $100 \mathrm{pg} / \mathrm{ml} 17 \beta-\mathrm{E}_{2}$, DES failed to enhance the AMPH-stimulated striatal DA release as compared to the control $\left(F_{1,11}=.01, P>0.90 ; F i g .7 A\right)$. DES also lacked any significant effect of enhancement even when the concentration was at 5 or 10 times as high $\left(F_{2,15}=\right.$ 1.08, P > 0.30; Fig. 7B). As in the case of experiments with catechol estrogens, baseline DA or DA release during exposure to estrone, estriol, or DES were not different from that of the controls (Table 1).

\section{Conjugated Estrogen}

E-BSA significantly potentiated striatal DA release induced by $\mathrm{AMPH}$ as compared to the control group $\left(F_{1,37}=4.80, P<0.05 ; F i g .8\right)$. This effect was seen in the absence of any difference in basal or Pre-AMPH striatal DA release (Table 1). Post-hoc tests indicated
TABLE I. Striatal dopaminerelease prior to AMPH

\begin{tabular}{|c|c|c|c|}
\hline Treatment group & Sample size & $\begin{array}{l}\text { Basal DA } \\
\text { release rate }{ }^{1}\end{array}$ & $\begin{array}{c}\text { DA release rate } \\
\text { pre-AMPH }^{2}\end{array}$ \\
\hline $4-\mathrm{OHE}_{2}(185 \mathrm{pM})$ & 6 & $5.2 \pm 1.3$ & $4.1 \pm 0.5$ \\
\hline $4-\mathrm{OHE}_{2}(740 \mathrm{pM})$ & 7 & $7.5 \pm 1.4$ & $4.1 \pm 0.5$ \\
\hline Vehicle & 4 & $7.5 \pm 0.9$ & $5.1 \pm 0.9$ \\
\hline $2-\mathrm{OHE}_{2}(185 \mathrm{pM})$ & 6 & $10.5 \pm 1.7$ & $7.1 \pm 1.3$ \\
\hline $2-\mathrm{OHE}_{2}(740 \mathrm{pM})$ & 7 & $7.7 \pm 0.8$ & $5.9 \pm 0.5$ \\
\hline Vehicle & 5 & $9.2 \pm 1.7$ & $4.9 \pm 0.5$ \\
\hline $2-\mathrm{MeE}_{2}(210 \mathrm{pM})$ & 6 & $11.1 \pm 1.6$ & $5.1 \pm 0.7$ \\
\hline $2-\mathrm{MeE}_{2}(2.1 \mathrm{nM})$ & 6 & $12.8 \pm 2.6$ & $6.0 \pm 1.7$ \\
\hline Vehicle & 6 & $12.7 \pm 2.4$ & $6.0 \pm 1.4$ \\
\hline estrone (210 pM) & 4 & $11.8 \pm 2.4$ & $4.1 \pm 1.0$ \\
\hline Vehicle & 4 & $13.7 \pm 4.2$ & $4.7 \pm 1.6$ \\
\hline estrone ( $2.1 \mathrm{nM})$ & 6 & $15.2 \pm 2.0$ & $8.9 \pm 0.9$ \\
\hline Vehicle & 5 & $14.0 \pm 2.4$ & $6.4 \pm 1.2$ \\
\hline estriol (370 pM) & 6 & $6.1 \pm 1.0$ & $4.4 \pm 0.6$ \\
\hline estriol (3.7 nM) & 7 & $6.2 \pm 0.7$ & $4.2 \pm 0.4$ \\
\hline Vehicle & 6 & $6.8 \pm 1.3$ & $3.8 \pm 0.5$ \\
\hline DES (370 pM) & 8 & $12.0 \pm 1.7$ & $6.4 \pm 1.1$ \\
\hline Vehicle & 5 & $1.9 \pm 1.4$ & $6.2 \pm 0.3$ \\
\hline DES (1.8 nM) & 6 & $7.4 \pm 0.6$ & $4.3 \pm 0.6$ \\
\hline DES (3.7 nM) & 6 & $6.4 \pm 0.5$ & $4.5 \pm 0.5$ \\
\hline Vehicle & 6 & $6.9 \pm 1.1$ & $5.2 \pm 0.5$ \\
\hline E-BSA (510 pM) & 22 & $6.6 \pm 0.7$ & $6.1 \pm 1.3$ \\
\hline $\mathrm{BSA}(410 \mathrm{pM})$ & 17 & $7.2 \pm 0.6$ & $4.9 \pm 0.6$ \\
\hline
\end{tabular}

${ }^{1}$ Mean \pm SEM of 3 baseline samples in $\mathrm{pg} / \mathrm{mg} / \mathrm{min}$.

2 Mean \pm SEM of DA release rate $(\mathrm{pg} / \mathrm{mg} / \mathrm{min})$ during intervals when exposed to the tested compounds or vehicle prior toAMPH stimulation. 


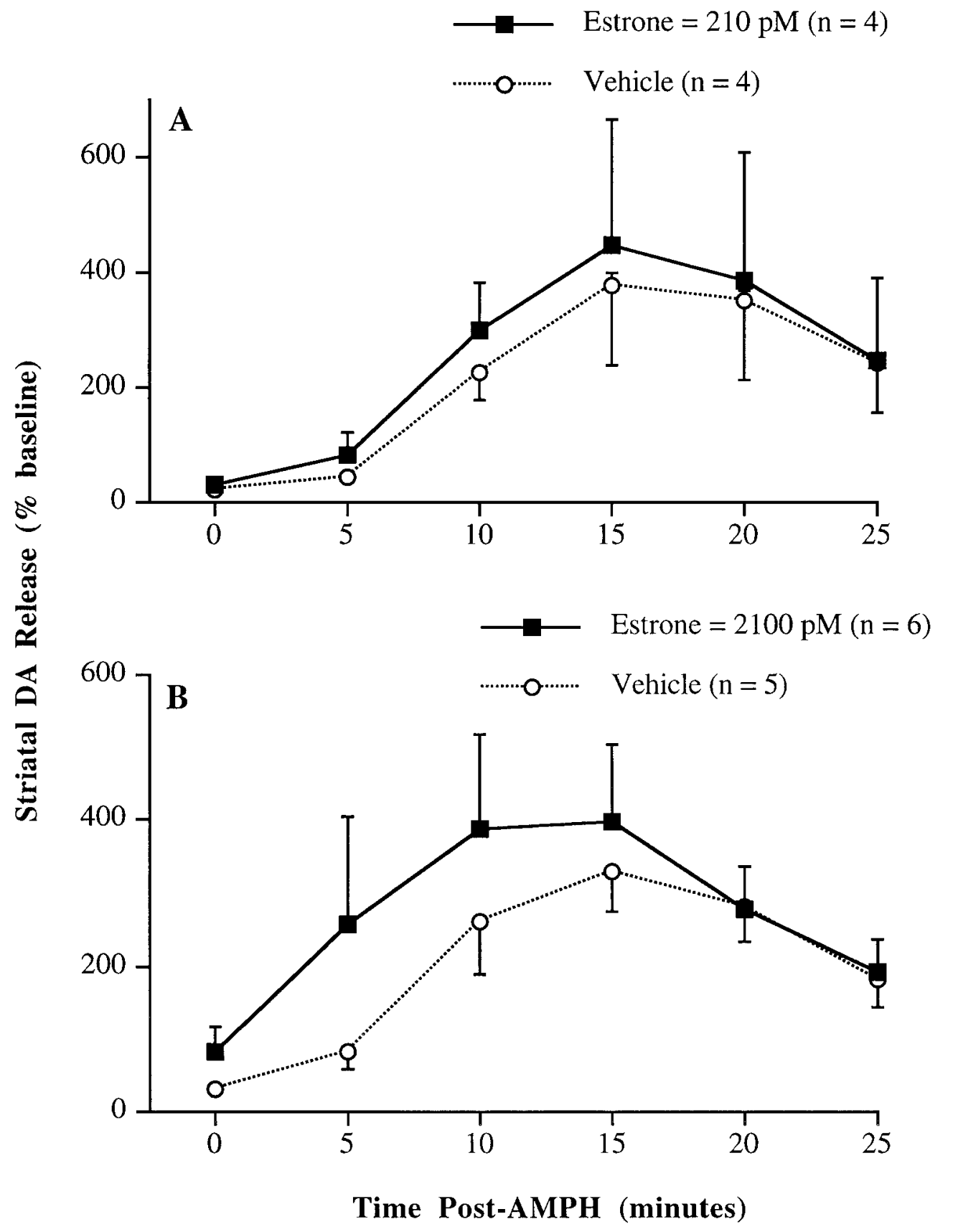

Fig. 5. Effects of estrone at $210 \mathrm{pM}(\mathbf{A})$ and $2.1 \mathrm{nM}$ (B) on AMPH-induced striatal DA release. See Figure 2 for superfusion procedures. None of the treatments with this compound induced a significant effect on DA release.

that in the first three, 5-minute intervals following $A M P H$, the DA concentration in the effluent was significantly enhanced by E-BSA treatment $(P<0.05)$.

\section{DISCUSSION}

The present results confirm and extend previous findings from this laboratory and show that estrogen exerts a rapid, steroid-specific action on striatal DA neurotransmission. In particular, catechol estrogens 4- $\mathrm{OHE}_{2}$ and $2-\mathrm{OHE}_{2}$, and the estrogen conjugate E-BSA enhance $A M P H$-induced $D A$ release from striatal tissue of OVX rats. Methoxylated estradiol, $2-\mathrm{MeE}_{2}$, estradiol's metabolites estrone and estriol, and the nonsteroidal estrogen DES did not have significant effects. These results indicate that the enhancement by estrogen of striatal DA activity is likely to be mediated by a 


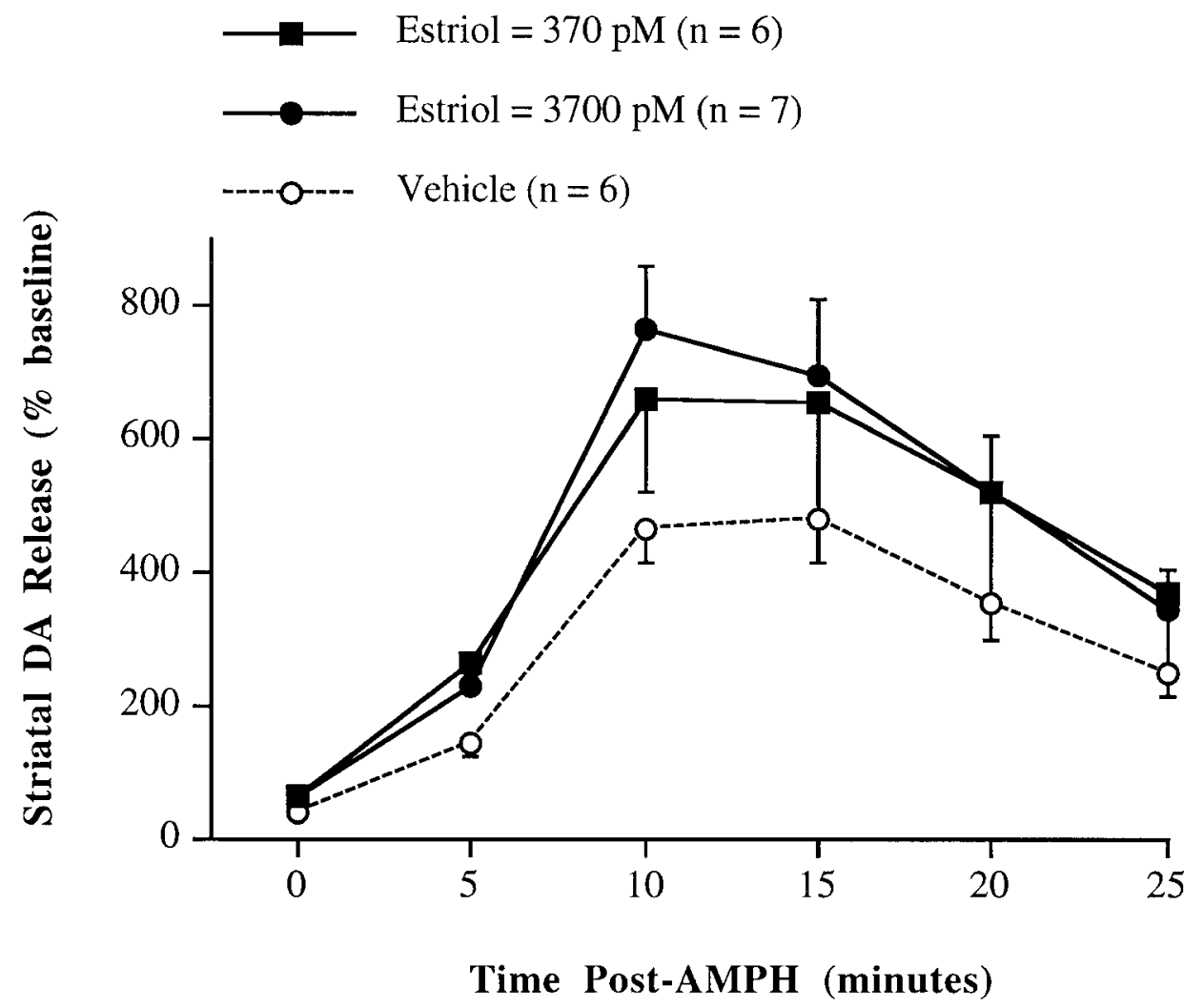

Fig. 6. Effects of estriol at $370 \mathrm{pM}$ and $3.7 \mathrm{nM}$ on $\mathrm{AMPH}$-induced striatal DA release. See Figure 2 for superfusion procedures. None of the concentrations of estriol significantly altered the time course of DA release as compared to the control group.

specific membrane binding site. Such an idea has been reinforced by demonstrations of steroid binding sites on neural membrane in other preparations (Majewska et al., 1986; Ramirez et al., 1996; Towle and Sze, 1983), and progesterone membrane binding sites in the striatum (Ramirez et al., 1985, 1990, 1996; Ramirez and Zheng, 1996). Furthermore, it suggests that hydroxylation on the A-ring and the steroidal configuration might be major factors that determine the affinity and/or potency of the estrogen compounds at the binding site in the striatum (Fig. 1).

When looking for structural and chemical properties of estrogens that might be relevant for the binding specificity, the sterane ring structure characteristic of all the steroids and the hydroxyl group(s) attached should be considered. This is because these features are helpful for comparing the membrane site with the known properties of the intracel lular estrogen receptor. First, the two representative catechol estrogens, 4-OHE $\mathrm{OH}_{2}$ and $2-\mathrm{OHE}_{2}$, are examined. Because of their natural occurrence in the brain and the periphery, these two compounds are believed to play important roles in the hormonal regulation of endocrine and neuroendocrine functions (Ball and Knuppen, 1990). Although both of them are thought to be capable of interacting with the classical estrogen receptor (J ellinck et al., 1981), there arestriking differences between the potencies of 2-OH $\mathrm{E}_{2}$ and $4-\mathrm{OHE}_{2}$ (Ball and Knuppen, 1990). For example, the uterotrophic effects of 4-OHE $E_{2}$ are indistinguishable from those of $17 \beta-E_{2}$; whereas $2-\mathrm{OHE}_{2}$ affects uterine growth only as a weak estrogen (Franks et al., 1982). In the pituitary, 4-OHE 2 potently inhibits $\mathrm{LH}$ levels, mimicking the effect of $17 \beta-\mathrm{E}_{2}$. $2-\mathrm{OHE}_{2}$ fails to do so, but is able to reverse the effect of $17 \beta-E_{2}$ (Franks et al., 1981). Similarly, $4-\mathrm{OHE}_{2}$ is equipotent to $17 \beta-\mathrm{E}_{2}$, while 2-OHE $\mathrm{E}_{2}$ is ineffective, in the induction of progestin binding sties in the hypothalamus, pituitary, and the uterus of OVX rats (Kirchhoff et al., 1983). Thus, hydroxylation of estradiol at C-2 vs. C-4 position can differentially alter the physiological properties of estrogen.

Similar to their relative potencies at the classical estrogen receptor, 4-OHE 2 in the present experiment appears to be a potent estrogen agonist. $2-\mathrm{OHE}_{2}$ only had marginal effects, and $2-\mathrm{MeE}_{2}$ is not effective at all. This relationship may bea result of the relative binding affinity, as in the case for the intracellular estrogen receptor. Merriam et al . (1980) have shown that 4-OHE 2 binds as tightly as $17 \beta-E_{2}$ to the cytosol estrogen receptor in the hypothalamus, pituitary, and uterus. $2-\mathrm{OHE}_{2}$ does less so, and $2-\mathrm{MeE}_{2}$ shows no binding affinity. These receptor affinities roughly parallel the 


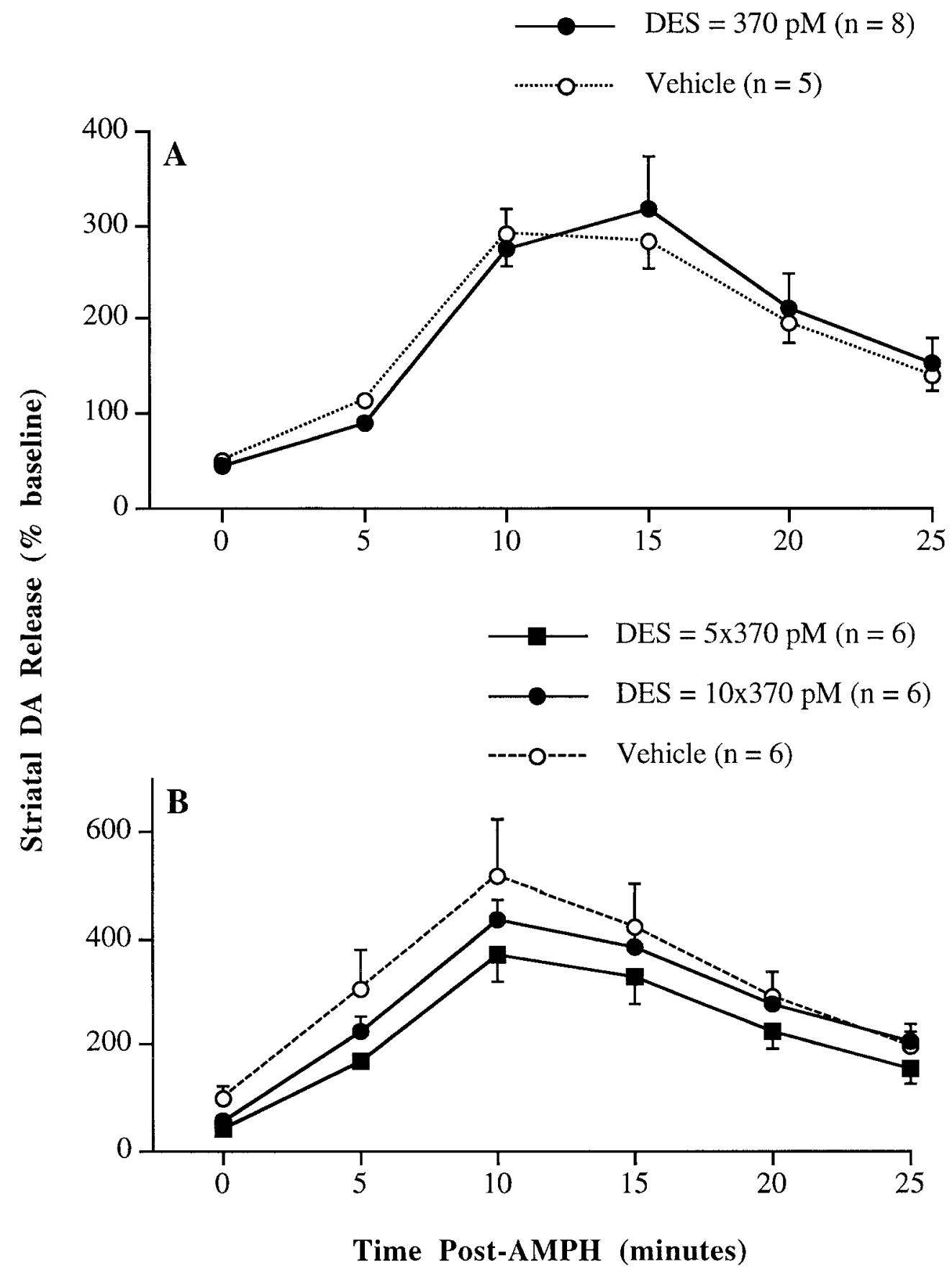

Fig. 7. Effects of various doses of DES on AMPH-induced striatal DA release Treatment procedure followed the description in Figure 2. DES at the $370 \mathrm{pM}$ (A) was tested separately from the other two higher doses of DES (1.85 and $3.7 \mathrm{nM}$; B). At all the doses tested, there was no significant difference among treatment groups.

potencies of these compounds in altering gonadotrophin secretion (Franks et al., 1980; Martucci and Fishman, 1979). For the intracellular estrogen receptor, 2-hydroxylation derivatives have lower affinity to the estrogen receptor than does 4-hydroxylation, and methoxylation of the resultant catechol estrogens essentially abolishes receptor binding activity (Martucci and
Fishman, 1979). Hence, the estrogen binding site in the striatum seems to share some structural homology to the intracel lular estrogen receptor. Specifically, hydroxylation at the A ring, especially at C-4 position, may be critical for the ligand binding, and hence the efficacy of theresponse. By contrast, C-2 hydroxylation and subsequent methoxylation attenuate the binding affinity. 

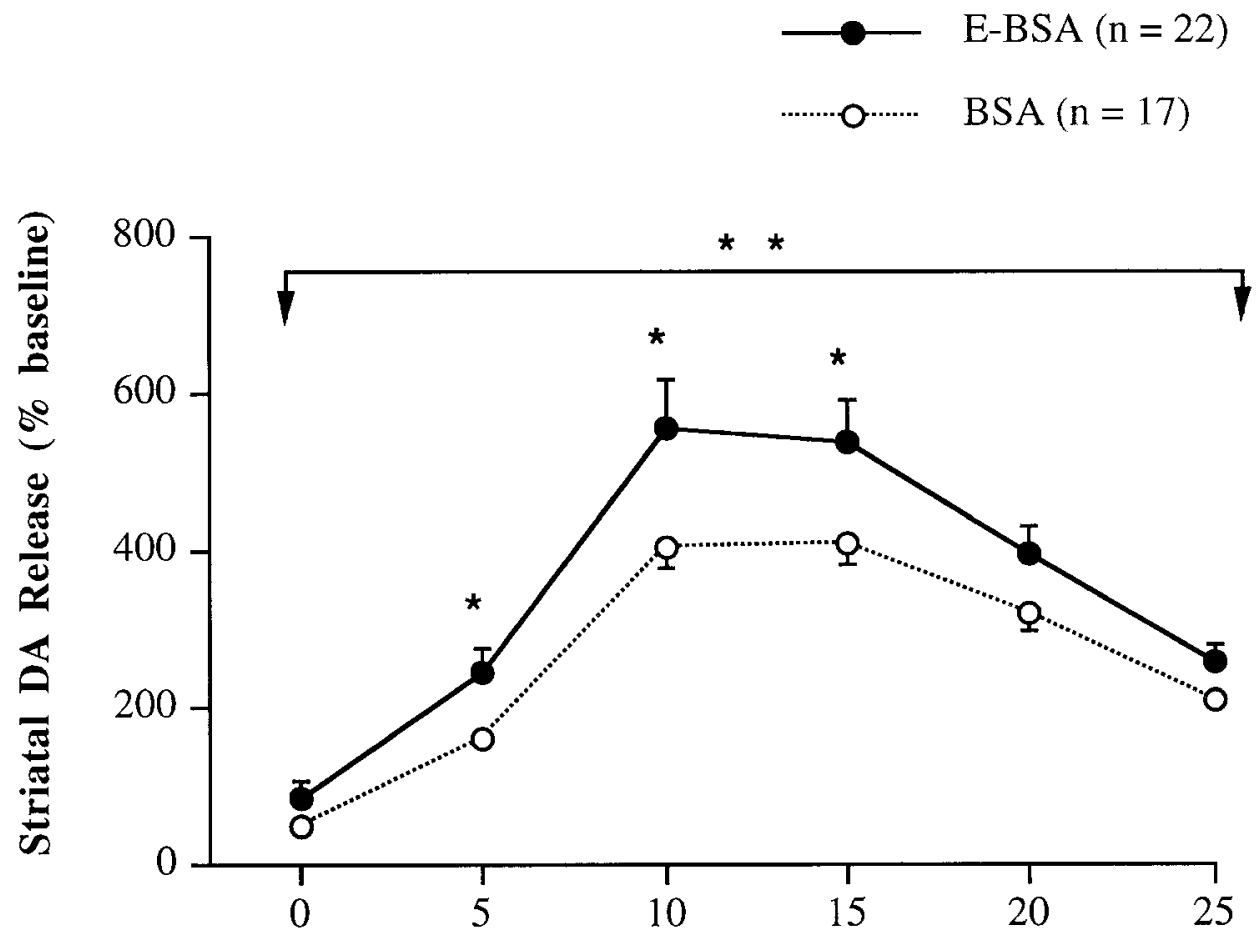

Time Post-AMPH (minutes)

Fig. 8. Effects of E-BSA on AMPH-induced striatal DA release. Superfusion procedure followed the description in Figure 2. ${ }^{* *}$ Main effect of treatment showing a significant difference between the two groups $(\mathrm{P}<.05)$. *Significantly different from the control at 5,10 , and 15 minutes after stimulation with AMPH $(\mathrm{P}<.05)$.

In general, substitution of a 2- or 4-hydroxyl group on the A-ring changes the biological properties of the estrogen molecule: it not only al ters the binding characteristics of the molecule to the receptor, but also affects the nature and extent of the possible interactions between estrogen and catechol amine neurotransmitter systems (Ghraf and Hiemke, 1983). As to the effects of catechol estrogens on the DA neurotransmission described above, a possibility remains that $2-$ and $4-\mathrm{OHE}_{2}$ may interact directly with DA receptors in the striatum. I n fact, experimental evidence exists that catechol estrogens are capable of binding to DA receptors. In the anterior pituitary, Schaeffer and Hsueh (1979) have demonstrated that $2-\mathrm{OHE}_{2}$ potently inhibits $\left[{ }^{3} \mathrm{H}\right]$ spiroperidol binding to DA receptors in vitro. In the striatum, $2-\mathrm{OHE}_{2}$ was the most potent compound among the steroids tested to compete for ligand binding to DA receptors (Paden et al., 1982). However, in both cases, $17 \beta-E_{2}$ is not effective in competing for DA receptors binding. In the present experiments, 4- $\mathrm{OHE}_{2}$ exhibits similar, potent effects to that of $17 \beta-\mathrm{E}_{2}$ on $\mathrm{AMPH}$ induced DA release (Becker, 1990b), whereas 2-OHE 2 has only minor effects on the DA release. This order of relative potency seems to conflict with the binding activity to the DA receptors. F urthermore, modulation by estrogen of AMPH-evoked striatal DA release has been shown to be a presynaptic effect, as oppose to a postsynaptic one (Becker and Beer, 1986). Therefore, modulation of DA release by the effect of estrogenic compounds on the estrogen binding site, rather than on DA receptors, seems most likely to mediate the effect reported. However, the present results do not eliminate the possibility that estrogen interacts with DA autore ceptors to affect DA release.

It should be mentioned that the higher dose of 4-OHE $\mathrm{E}_{2}$ appears to be less effective than the lower dose at enhancing AMPH-induced DA release. A bell-shaped dose response curve has al so been observed in the effect of $17 \beta-E_{2}$ on $\mathrm{KCl}$-stimulated striatal DA release using the same superfusion procedure (Becker, 1990b). It is possible that decreased efficacy at higher concentrations of $4-\mathrm{OHE}_{2}$ reflects the mechanism through which estrogen interacts with its receptor and/or non-specific effects on neuronal membranes (for discussion see Becker, 1990b).

M ost likely, at high concentrations non-specific interactions between steroi dal compounds and the cell membrane are interfering with the efficacy of the hormoneto bind the receptor and/or interferring with the G-protein effector system. That is, the hydrophobic nature of the 
steroids may allow them to intercal ate with phospholipids, thereby disrupting the organization of the lipid bilayer of membrane (Wong et al., 1996). As a consequence, we postulate that the functional properties of membrane proteins, such as receptor binding or dissociation of G-proteins within the membrane, are hindered by an al tered membrane structure.

In contrast to the potency of catechol estrogens, neither estrone or estriol, the estrogens derived via alternative metabolic pathways, show significant effect on striatal DA release. These findings argue in favor of the specificity and uniqueness of the effects of estrogen on striatal DA release. Estrone, estradiol, and estriol are equipotent uterotrophic agents when administered in a continuous manner (Anderson et al., 1975; Miller, 1969), although estrone and estriol do not bind to the cytosol estrogen receptor as tightly as estradiol in uterus, pituitary and hypothalamus (Martucci and Fishman, 1976; Merriam et al., 1980). These differences suggest that the membrane estrogen binding site in the striatum may differ from the intracellular estrogen receptor at least in the ligand structural requirement for $D$ ring. Modifications at C-16 or C-17 may attenuate the binding affinity, leading to a lack of response. It is also possible that estrone and estriol bind to the receptor with similar affinities as $E_{2}$, but are unable to induce an effect dueto the transient receptor occupancy (Anderson et al., 1972, 1975). However, it has been suggested that the addition of a hydroxyl group at C-16 is important for the ligand binding to the membrane binding site in the striatum. This is because estriol, but not estrone, is as effective as $17 \beta-E_{2}$ in the inhibition of L-type calcium current in striatal neurons (Mermelstein et al., 1996). The differences in the mode of hormone administration and the sensitivity of the physi ol ogical response examined may have to be considered to account for the discrepancy in these results.

The most distinct feature of the membrane binding site in the striatum may have to do with the steroidal specificity, as demonstrated by the effects of DES on striatal DA release. DES is a potent, non-steroidal estrogen analog in the uterus that induces uterine growth (Branham et al., 1993; Grunert et al., 1986). It also mimics estrogen in the hypothalamus and pituitary to regulate hormone secretion (Halling, 1992; J ordan and Lieberman, 1984). These effects are mediated by the intracellular estrogen receptor since DES resembles $17 \beta-E_{2}$ in uterine nuclear estrogen receptor binding (Attardi and Happe, 1986). In the present experiment, however, DES fails to exhibit any estrogenic effect, even at high doses. This suggests that the steroidal structures of estrogenic compounds are critical for the enhancement on striatal DA release. DES has also been found to act as an estrogen antagonist when interacting with non-genomic estrogen receptors in guinea pig hypothalamus neurons (Lagrange et al., 1997). $17 \beta-E_{2}$ rapidly attenuates $\mu$-opioid-induced hy- perpolarization. DES blocks the nongenomic effect of estrogen without showing $\mathrm{E}_{2}$-like response (Lagrange et al., 1997). Whether DES is an estrogen antagonist in the striatum remains to be determined. However, the fact that it does not mimic the effect of estrogen on AMPH-induced striatal DA release supports the idea that the receptor binding site is distinct from the intracellular estrogen receptor in the uterus with respect to the steroidal specificity.

There are at least two pieces of direct evidence supporting the idea that effects reported are mediated by a membrane receptor for estrogen in the striatum: (1) estradiol conjugated to BSA is as effective as estradiol at enhancing $A M P H$-induced DA release in the present experiment; and (2) E-BSA is as effective as $17 \beta-E_{2}$ in inhibiting the L-type calcium current in striatal neurons (Mermelstein et al., 1996). The question of whether the effect of E-BSA in the striatum is mediated by a small amount of estrogen that has dissociated from the BSA and can diffuse into the cell does seem particularly germane in this system, as cells with classical estrogen receptors are not found in the striatum (Pfaff and Keiner, 1973; Simerly et al., 1990). Furthermore, in whole cell-clamp experiments with 100 pM estradiol in the recording electrode, which dialyzes with the contents of the cell to produce a concentration of $100 \mathrm{pM} 17 \beta-\mathrm{E}_{2}$ inside the cell, $1 \mathrm{pM}$ $17 \beta-E_{2}$ is still effective at producing a decrease in L-type calcium current when applied extracellularly, arguing that the effect of estradiol in the striatum is extracellular (Mermelstein et al., 1996). Finally, a membrane-associated estrogen binding site has been demonstrated in the striatum (Zheng et al., 1996). Using E-BSA, Zheng and colleagues have been able to show a specific membrane binding site in synaptosomal membrane preparations from the cerebellum, hypothalamus, olfactory bulb, and corpus striatum (Zheng et al., 1996). These experiments lend support to the assumption that estrogen is acting at an extracellular membrane binding site, rather than the classical intracellular estrogen.

In conclusion, the results presented here support the idea that estrogenic compounds rapidly modulate AMPH-induced striatal DA release via a steroidspecific, membrane-associated receptor mechanism(s). This effect appears to be influenced by two main factors: (1) the position of constituents added to the basic estrogen ring structure, with hydroxylation on the A ring being more effective than modifications on the $D$ ring, and (2) the 3-D configuration of the receptor binding site, which appears to require a rigid steroi dal ring structure for receptor activation. These results are important for two reasons. First, they demonstrate the pharmacological differences between estrogen receptors in the striatum and the classical estrogen receptor, and may help in the eventual isolation and cloning of the receptor. Second, these results may beimportant for 
our understanding of how hormone replacement therapy (HRT) can produce different psychological effects depending on the drug used. Premarin ${ }^{\circledR}$ is one of the more widely prescribed HRT drugs, and contains high concentrations of estrone, as well as other estrogen metabolites in lower concentrations, but does not contain $17 \beta-E_{2}$. So, enhanced striatal DA activity or sensorimotor function are not likely to be an effect of Premarin ${ }^{\circledR}$ treatment if, in fact, the positive effects of estrogen on sensorimotor function in humans (Hampson, 1990) are mediated by the mechanism under investigation here. As we come to understand the variety of mechanisms through which estrogenic compounds can interact with the brain and peripheral tissues, our ability to target specific subsets of receptors may lead to significant improvements in HRT.

\section{ACKNOWLEDGMENTS}

This research was supported by grant NSF BNS9021900 to J .B.B.; L.X. was supported in part by training grant NICHD 5T32-HD07048.

\section{References}

Anderson, J .N., Clark, J .H., and Peck, E.J . (1972) The relationship between nuclear receptor-estrogen binding and uterotrophic responses. Biochem. Biophys. Res. Commun., 48:1460-1468.

Anderson, J.N., Peck, E.J ., and Clark, J.H. (1975) Estrogen-induced uterine responses and growth: relationship to receptor estrogen binding by uterine nuclei. Endocrinol ogy, 96:160-167.

Attardi, B., and Happe, H.K. (1986) Comparison of the physicochemical properties of uterine nuclear estrogen receptors bound to estradiol or 4-hydroxytamoxifen. Endocrinol ogy, 119:904-915.

Ball, P., and Knuppen, R. (1990) Formation, metabolism, and physiol ogic importance of catecholestrogens. Am. J . Obstet. Gynecol., I 21: 63-70.

Becker, J.B. (1990a) Estrogen rapidly potentiates amphetamine induced striatal dopamine release and rotational behavior during microdialysis. Neurosci. Lett., 118:169-171.

Becker, J .B. (1990b) Direct effect of 17 $\beta$-estradiol on striatum: sex differences in dopamine release. Synapse, 5:157-164.

Becker, J.B., and Beer, M.E. (1986) The influence of estrogen on nigrostriatal dopamine activity: behavioral and neurochemical evidence for both pre and postsynaptic components. Behav. Brain Res., 19: 27-33.

Becker, J .B., Snyder, P.J ., Miller, M.M., Westgate, S.A., and J enuwine, M.J. . (1987) The influence of estrous cycle and intrastriatal estradiol on sensorimotor performance in the female rat. Pharmacol. Biochem. Behav., 27:53-59.

Blackmore, P.F., Neulen, J ., Lattanzio, F., and Beebe, S.J . (1991) Cell surface-binding sites for progesterone mediate calcium uptake in human sperm. J . Biol. Chem., 266:18655-18659.

Branham, W.S., Zehr, D.R., and Sheehan, D.M. (1993) Differential sensitivity of rat uterine growth and epithelium hypertrophy to estrogens and antiestrogens. Proc. Soc. Exp. Biol. Med., 203:297-303.

Castner, S.A., Xiao, L., and Becker, J.B. (1993) Sex differences in striatal dopamine: In vivo microdialysis and behavioral studies. Brain Res., 610:127-134.

Di Paolo, T., Rouillard, C., and Bedard, P. (1985) 17 beta-Estradiol at a physiological dose acutely increases dopamineturnover in rat brain. Eur. J. Pharmacol., 117:197-203.

Franks, S., Ball, P., Naftolin, F., and Ruf, K.B. (1980) Effect of catechol oestrogens on induced ovulation in the immature rat. J . Endocrinol., 86:263-268.

Franks, S., MacLusky, N.J ., Naish, S.J ., and Naftolin, F. (1981) Actions of catechol oestrogens on concentrations of serum luteinizing hormone in the adult castrated rat: Various effects of 4- hydroxyoestradiol and 2-hydroxyoestradiol. J . Endocrinol., 89:289-295.

Franks, S., MacLusky, N.J ., and Naftolin, F. (1982) Comparative pharmacology of oestrogens and catechol oestrogens: actions on the immature rat uterus in vivo and in vitro. J . Endocrinol., 94:91-98.
Ghraf, R., and Hiemke, C. (1983) Interaction of catechol estrogens with catecholamine synthesis and metabolism. In: Catechol Estrogens. G. R. Merriam and M. B. Lipsett, eds. Raven Press, New York. Grunert, G., Porcia, M., and Tchernitchin, A.N. (1986) Differential potency of oestradiol-17 beta and diethylstilboestrol on separate groups of responses in the rat uterus. J . Endocrinol., 110:103-114.

Halling, A. (1992) Alterations in hypothalamic and pituitary hormone level sinduced by neonatal treatment of female mice with diethylstilbestrol. Reprod. Toxicol., 6:335-346.

Hampson, E. (1990) Variations in sex-related cognitive abilities across the menstrual cycle. Brain Cognition, 14:26-43.

Heritage, A., Stumpf, W., Sar, M., and Grant, L. (1980) Brainstem catecholamine neurons are target sites for sex steroid hormones. Science, 207:1377-1379.

J ellinck, P.H., Krey, L., Davis, P.G., Kamel, F., Luine, V., Parsons, B., Roy, E.J ., and M CE wen, B.S. (1981) Central and peripheral action of estradiol and catecholestrogens administered at low concentration by constant infusion. Endocrinology, 108:1848-1854.

J ordan, V.C., and Lieberman, M.E. (1984) Estrogen-stimulated prolactin synthesis in vitro. Classification of agonist, partial agonist, and antagonist actions based on structure. Mol. Pharmacol., 26:279-285.

Ke, F.C., and Ramirez, V.D. (1990) Binding of progesterone to nerve cell membranes of rat brain using progesterone conjugated to $125 \mathrm{I}$-bovine serum al bumin as a ligand. J. Neurochem., 54:467-472.

Kirchhoff, I., Reinhardt, W., Grunke, W., Ghraf, R., Ball, P., and Knuppen, R. (1983) Induction of cytosolic progestin binding sites by catecholestrogens in rat pituitary gland and uterus: Different potencies of 2- and 4- hydroxyestradiol. J. Neurochem., 40:474-480.

Lagrange, A.H., Ronnekleiv, O.K., and Kelly, M.J . (1997) Modulation of $\mathrm{G}$ protein-coupled receptors by an estrogen receptor that activates PKA. Mol. Pharmacol., 51:605-612.

Liu, Z., and Patino, R. (1993) High-affinity binding of progesterone to the plasma membrane of Xenopus oocytes: Characteristics of binding and hormonal and developmental control. Biol. Reprod. 49:980-988.

Majewska, M.D., Harrison, N.L., Schwartz, R.D., Barker, J .L., and Paul, S.M. (1986) Steroid hormone metabolites are barbiturate-like modulators of the GABA receptor. Science, 232:1004-1007.

Martucci, C., and Fishman, J. (1976) Uterine estrogen receptor binding of catecholestrogens and of estetrol (1,3,5(10)-estratriene 3,15al pha,16al pha,17beta-tetrol). Steroids, 27:325-333.

Martucci, C.P., and Fishman, J . (1979) I mpact of continuously administered catechol estrogens on uterine growth and luteinizing hormone secretion. Endocrinology, 105:1288-1292.

McEwen, B. (1979) Steroid hormone interactions with the brain: Cellular and molecular aspects. Rev. Neurosci., 4:1-30.

McE wen, B.S. (1994) Steroid hormone actions on the brain: When is the genome involved? Horm. Behav., 28:396-405.

Mermelstein, P.G., Becker, J .B., and Surmeier, D.J . (1996) Estrogen reduces calcium currents in rat neostriatal neurons via a membrane receptor. J . Neurosci., 16:595-604.

Merriam, G.R., MacLusky, N.J ., Picard, M.K., and Naftolin, F. (1980) Comparative properties of the catechol estrogens, I: Methylation by catechol-O-methyltransferase and binding to cytosol estrogen receptors. Steroids, 36:1-11.

Miller, B.G. (1969) The relative potencies of oestriol, oestradiol and oestrone on the uterus and vagina of the mouse. J . Endocrinol., 43:563-570.

Nabekura, J ., Oomura, Y., Minami, T., Mizuno, Y., and Fukuda, A. (1986) Mechanism of the rapid effect of 17 beta-estradiol on medial amygdala neurons. Science, 233:226-228.

Naish, S.J., and Ball, P. (1981) Catecholestrogens and induction of sexual behavior in the ovariectomized rat. Neuroendocrinology, 32:225-228.

Paden, C.M., McEwen, B.S., Fishman, J ., Snyder, L., and DeGroff, V. (1982) Competition by estrogens for catecholamine receptor binding in vitro. J . Neurochem., 39:512-520.

Paul, S.M. and Skolnick, P. (1977) Catechol oestrogens inhibit oestrogen elicited accumulation of hypothalamic cyclic AMP suggesting role as endogenous anti-oestrogens. Nature, 266:559-561.

Pfaff, D., and Keiner, M. (1973) Atlas of estradiol-concentrating cells in the central nervous system of the rat. Comp. Neurol., 151:121-158.

Ramirez, V.D. and Zheng, J . (1996) Membrane sex-steroid receptors in the brain. Front. Neuroendocrinol., 17:402-439.

Ramirez, V.D., Kim, K., and Dluzen, D. (1985) Progesterone action on the LHRH and the nigrostriatal dopamine neuronal systems: in vitro and in vivo studies. Recent Prog. Horm. Res., 41:421-472.

Ramirez, V.D., Dluzen, D.E., and Ke, F.C. (1990) Effects of progester- 
one and its metabolites on neuronal membranes. Ciba Found. Symp., 153:125-141.

Ramirez, V.D., Zheng, J ., and Siddique, K.M. (1996) Membrane receptors for estrogen, progesterone, and testosterone in the rat brain: fantasy or reality. Cell. Mol. Neurobiol., 16:175-198.

Schaeffer, J.M., and Hsueh, A.J . (1979) 2-Hydroxyestradiol interaction with dopamine receptor binding in rat anterior pituitary. J . Biol. Chem., 254:5606-5608.

Simerly, R.B., Chang, C., Muramatsu, M., and Swanson, L.W. (1990) Distribution of androgen and estrogen receptor mRNA-containing cells in the rat brain: an in situ hybridization study. J . Comp. Neurol., 294:76-95.

Stumpf, W.E., and Sar, M. (1976) Steroid hormone target sites in the brain: The differential distribution of estrogen, progestin, androgen and glucocorticosteroid. J . Steroid Biochem., 7:1163-1170.

Tischkau, S.A., and Ramirez, V.D. (1993) A specific membrane binding protein for progesterone in rat brain: Sex differences and induction by estrogen. Proc. Natl. Acad. Sci. U.S.A., 90:1285-1289.

Towle, A.C., and Sze, P.Y. (1983) Steroid binding to synaptic plasma membrane: Differential binding of glucocorticoids and gonadal steroids. J . Steroid Biochem., 18:135-143.

Wong, M., and Moss, R.L. (1991) Electrophysiological evidence for a rapid membrane action of the gonadal steroid, 17 beta-estradiol, on CA1 pyramidal neurons of the rat hippocampus. Brain Res., 543:148-152.

Wong, M., Thompson, T.L., and M oss, R.L. (1996) Nongenomic actions of estrogen in the brain: Physiological significance and cellular mechanisms. Crit. Rev. Neurobiol., 10:189-203.

Zheng, J., Ali, A., and Ramirez, V.D. (1996) Steroids conjugated to bovine serum albumin as tools to demonstrate specific steroid neuronal membrane binding sites. J. Psychiatry Neurosci., 21:187-197. 